\title{
Crítica profética a los imperialismos y a la religión nacionalista de Israel*
}

\section{RAFAEL DE SIVATTE Centro de Reflexión Teológica, San Salvador}

Muchos y muy graves son los problemas del tercer mundo y de América Latina que afectan directamente a la vida y a la muerte de los hombres y de pueblos enteros. También el pueblo de Israel, en su larga historia, se vio sumergido en ellos, los padeció y trató de darles una respuesta, respondiendo a veces de acuerdo a su fe y muchas veces pervirtiéndola. El estudio del Antiguo Testamento puede iluminar, por lo tanto, aunque sin caer en anacronismos de aplicaciones inmediatistas, la realidad de los problemas actuales y sobre todo puede iluminar cómo se debe responder a ellos desde la palabra de Dios.

En este trabajo me voy a concentrar en la visión crítica de los profetas de Israel que actuaron entre los años 750 y 350 a.C., es decir, en las épocas de mayores crisis internacionales, nacionales y sociales en los dos reinos, del norte $o$ Israel, y del sur o Judá, que acabaron con los mismos.

Aludiré brevemente, por más conocida y tratada, a la crítica a la injusticia, para concentrarme en otros problemas graves, ayer como hoy, como son los imperialismos, el armamentismo, el sometimiento a las grandes potencias, etc. Hay que mencionar también el fenómeno del nacionalismo teocrático de Israel, con su analogia en un mundo occidental cristiano, basado en una manipulación de la elección, y el fenómeno de lo que se ha llamado nacionalcatolicismo que permite una religión alienante. Ante todo esto los profetas dirigen durísimas palabras en nombre de Dios; pero recuerdan siempre la utopía de Dios, que es a la vez exigencia de conversión y esperanza en un futuro más humano y más divino. Según esto, el trabajo está dividido en cinco partes, de las cuales las dos primeras serán tratadas en mayor extensión y sólo insinuadas las tres últimas:

- Este articulo está basado en una conferencia sobre la luz que el Antiguo Tesiamento puede aportar a algunos importantes problemas de nuestro mundo. Esto explica el estilo directo, más propio del lenguaje hablado, y que en lugar de aducir referencias científicas se haya preferido citar directamente a los profetas. Para profundizar en el tema puede consultarse J.L. Sicre, Los dioses olvidados, Madrid: Cristiandad, 1979, La justicia social en los profelos de Israel, Madrid: Cristiandad, 1985; R. Sivalte, "La práctica de la justicia, eriterio de discernimiento de la verdadera experiencia de fe según el Antiguo Testamento," en Varios, La justicia que brota de la fe, Santander: Sal Terrae, 1982, pp. 13-34. 
1. Crítica profética del imperialismo de las grandes potencias, de la política de alianzas y del militarismo.

2. Crítica profética del nacionalismo de Israel basado en su teología de la eleccion.

3. Crítica de la privatización de la nación en manos de unos pocos y de la desigualdad entre hermanos.

4. Crítica del nacionalyahvismo y de la religión alienante.

5. Anuncio profético de la utopía.

Digamos para terminar estas palabras introductorias que no se trata de un estudio sistemático, sino de presentar de forma sintética y en base a ejemplos importantes la crítica de los profetas, dejándoles hablar a ellos mismos, y de ahí las largas citas.

\section{La crítica profética del imperialismo de las grandes potencias, de la política de alianzas y del militarismo}

¿Se puede hablar de una situación imperialista en el mundo del que habla el Antiguo Testamento? Sí y desde siempre. Este imperialismo nace ya del interés geopolitico que tiene la zona de Canaán, situada entre las dos grandes superpotencias del llamado "creciente fértil," es decir, entre Egipto y los imperios mesopotámicos. Canaán, como lugàr de paso, como lugar donde colocar las propias mercancías, como fuente de algunos productos básicos, como muro de protección frente a la otra superpotencia, siempre sufrió el ser objeto de deseo de ambas.

Ya los grupos previos que luego fueron la base de Israel, es decir, los nómadas del desierto de Judá, los sedentarios de la zona filistea, los emigrantes en busca de subsistencia a tierras egipcias, estuvieron bajo esas presiones mencionadas, tenian que pagar el derecho de paso, se les imponían impuestos, eran esclavizados como mano de obra barata y explotada.

Con la unión de los grupos y el nacimiento de la nación, a partir de la experiencia común de la liberación del dominio egipcio, no se acabarán los afanes imperialistas de las superpotencias y, por lo tanto, sus presiones. Israel (o reino del norte) será conquistado y colonizado por el imperio asirio; Judá (o reino del sur) será destruido y deportado a Babilonia; el judaísmo, surgiendo del exilio, vivirá también bajo los imperios medo-persa, helenista o romano.

Dentro de esta perpetua situación imperialista del creciente fértil, fijemonos ahora en algunos momentos importantes de esta historia de presiones y veamos la posición de los profetas.

\section{a) Crisis y calda de Israel (740-72I)}

Con Tiglatpileser III (745-727), el imperio asirio, que había pasado momentos de gran debilidad, resurgió. Algunas pequeñas naciones pretendieron frenarlo; pero fueron vencidas. La mayoría de la zona, de un modo u otro, se hizo su tributaria. A la vista de este resurgimiento de Asiria, Egipto impulsó 
una coalición en contra, con la cual pretendia reunir a Siria, Israel, Arabia y Judá. El rey de Judá, aconsejado por Isaías, se resistió a entrar en dicha coalición y, en consecuencia, fue atacado por la misma. Pidió entonces, en contra de la opinión de Isaias, ayuda a Asiria, la cual encontró motivo y ocasión para intervenir, "en favor de un aliado," invadiendo toda la zona y dejando una parte del ejército en las fronteras egipcias. Aparte de esta invasión, Asiria apoyó a un tal Oseas en su golpe de Estado contra el rey de Israel, Pecaj, profundamente anti-asirio. Oseas vencib, pero se convirtió así en tributario de la potencia asiria. Todo esto ocurrió hacia el año 731 a.C. Esta alianza de Oseas con Asiria, con todo, no duró mucho. Aprovechando la muerte de Tiglatpileser III (hacia el 727) y la subida al trono asirio de Salmanasar V, presionado además por las facciones antiasirias del gobierno, Oseas se declaró índependiente, pero a costa de hacer alianza con el faraón egipcio, el cual, por otra parte, no resultó una gran ayuda. Salmanasar reunió fuerzas, vino contra Samaria (722), sitió la ciudad, se apoderó de ella en el 721, deshizo el reino y convirtió a lsrael en colonia asiria; con esto, el pequeño reino de Israel (norte) dejó de existir para siempre. Hasta aqui la turbulenta historia de la crisis y caida de Israel.

En medio de esta historia, como ha quedado claro y como muy bien nota J.L. Sicre en su libro Los dioses olvidados, la postura de los reyes de Samaria fue la de hacer alianzas convirtiéndose en tributarios de alguna de las grandes potencias y haciendo pactos militares con ellas. Está claro que estos pactos en muchas ocasiones resultaron casi obligados, dada la imposición de dichas potencias. El problema surgib cuando dichos pactos fueron realizados voluntariamente por los reyes de Israel. Tal es el caso, parece, del tributo pagado por Menajem al rey asirio para ser confirmado como rey y apoyado; tal es también el de Oseas cuando pidió ayuda a Asiria para dar el golpe de Estado a Pecajías que le llevó al poder, y asimismo el del mismo rey Oseas cuando se alió con Egipto con la intención de independizarse de Asiria. Son estos casos de pactos voluntarios los que provocaron la palabra del profeta Oseas, tal como se expone a continuación en algunos textos.

Efraim ha visto su dolencia y Judá su llaga. Efralm entonces ha ido a Asiria y Judá ha mandado mensaje al gran rey; pero éste no podrá sanarnos ni curar vuestra llaga. Porque yo soy como... Yo, yo mismo desgarraré y me iré, arrebataré y no habrá quien salve (Os. 5,13-14).

Se habla aqui de recurrir a las potencias extranjeras, en busca de la salud y la curación, sin caer en la cuenta de que éstas soblo dependen de Yahveh.

Efraim se mezcla con los pueblos, Efraim es una torta a la que no se ha dado la vuelta. Extranjeros devoran su fuerza, iy él no lo sabe! Ya las canas blanquean en él, iy él no lo sabe! El orgullo de Israel testifica contra él, pero no se vuelven a Yahveh su Dios; con todo esto, no le buscan. Efraim es cual ingenua paloma, sin cordura; llaman a Egipto, acuden a Asiria. Dondequiera que vayan, yo echaré mi red sobre ellos, como ave del cielo les haré caer, les visitaré por su maldad (Os. 7, 8-12). 
Vuelve a aparecer el recurso a los extranjeros como búsqueda de un camino falso que, dado el lenguaje usado por Oseas, resulta ser un camino idolátrico.

Ya que siembran viento, segarán tempestad: tallo que no tendrá espiga, que no dará harina; y si la da, extranjeros la tragarán. ¡Tragado ha sido Israel! Están ahora entre las naciones como un objeto que nadie quiere. Porque han subido a Asiria, ese onagro solitario; Efraím se ha comprado (con sus tributos) amores: aunque los compre entre las naciones, yo los voy a reunir ahora y pronto sufrisán bajo la carga del rey de principes (Asiria) (Os. 8, 7-10).

Alude asi a las alianzas que a la larga, si no a la corta, se tragan el pais tributario y éste acaba mal.

Olvida Israel a su Hacedor, edifica palacios; Judá multiplica las ciudades fuertes. Pero yo prenderé fuego a sus ciudades, que devorarán sus alcázares (Os. 8,14).

El tema de esta breve denuncia, en cambio, es la confianza en la fuerza militar y las fortificaciones. Es una confianza sin fundamento, pues de todo ello no quedará nada.

Efraim me ha rodeado de mentiras, de engafio la casa de Israel. Efralm se apacienta de viento, anda tras el solano todo el día; mentira y pillaje multiplica, hacen alianza con Asiria y llevan aceite a Egipto (Os. 12, 1-2).

Los dones ofrecidos a las potencias hacen pensar enseguida en una verdadera acción idolátrica de tomar a aquellas potencias como dioses. Esto no constituye una base segura. Todo es falsedad y engaño.

Asiria no nos salvará, no montaremos ya a caballo, y no diremos más

"Dios nuestro" a la obra de nuestras manos, oh tú, en quien halla compasión el huérfano (Os. 14,4).

Es ésta la confesión que demuestra al final del libro del profeta cuando la conversion es auténtica. En esta confesión no queda duda de que la autenticidad de la conversión y, por tanto, la seguridad del pueblo, está en el rechazo de las alianzas, de la fuerza militar y del culto a las imágenes. Impresiona, en este sentido, la equivalencia que se presupone entre idolatria y confianza en el pacto con extranjeros y en la fuerza militar.

De la lectura de estos textos se desprende cuál es el juicio de Oseas sobre la actitud de Israel que, en su debilidad, busca la salvación, el efecto, la fortaleza. Es una búsqueda por camino equivocado, pues está toda ella movida por su actitud idolátrica. Esta actitud idolátrica aparece con claridad en los verbos usados por Oseas en las denuncias antes vistas: "subir," "ir," "enviar mensajeros," "invocar," "hacer alianza," "ofrecer dones." Todas estas expresiones confirman que las ayudas buscadas por Israel en los ejércitos asirios o egipcios son vistas por Oseas como verdaderos actos de confianza en unos dioses falsos, como verdaderos actos de idolatría; por lo tanto, a la larga, llevarán al fracaso y a la ruina. 


\section{b) Momentos críticos para Judá en tiempo del profeta Isaías (740-70I)}

Nos encontramos en el momento en que Siria e Israel pretenden la colaboración de Judá contra Asiria. Judá se resistió y, ante el ataque de aquellos dos reinos, pidió ayuda a Asiria (734). Con esto quedó prácticamente como un país vasallo del imperio asirio: ha tenido que pagar un alto precio. Más adelante fueron creciendo en Judá los deseos de conseguir la independencia de Asiria; pero faltó la decisión (713-711). Finalmente, cuando murió el emperador asirio (705), el rey de Judá sucumbió a las presiones egipcias, hizo alianza con Egipto y se rebeló contra Asiria; esto provocó la invasión de los asirios, aunque éstos no consiguieron apoderarse de la capital, Jerusalén, y por lo tanto, del poder del reino.

La postura del profeta Isaias en todo este tiempo fue bastante clara. No favoreció nada que significara quitar valor al pacto único que podia producir seguridad, el pacto con Yahveh su Dios. Tenemos, además, algunos textos, posiblemente del momento en que los judios buscan la alianza con los filisteos, alianza propiciada por Egipto, en contra de Asiria, para conseguir la independencia. En estos textos aparece con claridad la denuncia contra dichas alianzas, pues significan una verdadera rebelión contra su Padre, una verdadera idolatria, una búsqueda de refugio y de acogida en Egipto, una falsa confianza en el armamento moderno de los egipcios. Aparece también cómo esta actitud va a recibir como respuesta la frustración y la caída de aquel que se esperaba que ayudase y al mismo tiempo del que esperaba ser ayudado.

¡Ay de los hijos rebeldes para ejecutar planes, que no son los míos, y para hacer libaciones de alianza, mas no a mi aire, amontonando pecado sobre pecado! Los que bajan a Egipto sin consultar a mi boca, para buscar apoyo en la fuerza de Faraón y ampararse a la sombra de Egipto. La fuerza del Faraón se les convertirá en verguenza, y el amparo de la sombra de Egipto, en confusión... todos llevaron presentes a un pueblo que les será útil, a un pueblo que no sirve de ayuda - ni de utilidad - sino de vergùenza y oprobio (Is. 30, 1-5).

iAy de los que bajan a Egipto por ayuda! En la caballeria se apoyan y fian en los carros porque son muchos; mas no han puesto su mirada en el santo de Israel ni a Yahveh han buscado. Pero también él es sabio, hará venir el mal,... se levantará contra la casa de los malhechores y contra la ayuda de los que obran la iniquidad. En cuanto a Egipto, es humano, no divino, y sus caballos, carne, y no espíritu; Yahveh extenderá su mano, tropezará el ayudador y caerá el ayudado y todos a una perecerán (Is. 31, 1-3).

Esta actitud de Isaías quizás es la misma que le mueve a decir las duras palabras contra el rey Ajaz, hacia el año 734, ("ore pues, casa de David: ¿te parece poco cansar a los hombres que cansas también a mi Dios? Pues bien, el Sefor mismo va a darte una señal: he aquí que una doncella está encinta y va a dar a luz un hijo y le pondrá por nombre Emmanuel" Is. 7, 13-14), cuando éste dice no querer pedir una señal de la cercanía de Dios para no tentarle, pero al mismo tiempo está pidiendo la ayuda de los ejércitos asirios en contra de la coalición siro-efraimita, reconociendo así a Asiria y a su fuerza militar como soberano y dios. 
Para Isaías, pues, estas alianzas militares con otros países no dan más fuerza que el adorar a un ídolo de madera que, si bien a la corta puede dar seguridad al adorador, a la larga es víctima de las llamas y de la destrucción y deja desnudo, vacio e inseguro a quien ha confiado en él.

c) Ultimos momentos críticos de Judá que llevan a su destrucción y al consiguiente exilio (609-587)

A la muerte en batalla del reformista rey Josías, a mano del faraón egipcio (609), cuando aquél intentaba impedir el paso a éste por territorio israelita, la imposición egipcia de Joaquín I, uno de los hijos de Josias, como rey, provoca una política egiplófila en la corte de Jerusalén. Babilonia, en represalia, hizo sentir su presión hasta someter a Judá en el año 603. Joaquín I, en la primera ocasión que se le presentó, se rebeló contra Babilonia (599); pero su rebelión le costó la muerte, la entrada de los ejércitos babilonios en Jerusalén, la imposición por parte de los vencedores de Sedecías, otro de los hijos de Josias, como rey-vasallo en Jerusalén, y la primera deportación de judios a Babilonia.

El rey Sedecías recibió continuas presiones egipcias y de sus propios ministros para que decidiera el levantamiento armado contra Babilonia. Finalmente, con la promesa de ayuda egipcia, se rebeló en el año 588 y esto supuso la destrucción de Jerusalén y su templo, la caida de Judá como nación y la segunda deportación, más masiva, de judios a Babilonia.

En este marco histórico, está claro que al profeta Jeremías no le interesan tanto los posibles pactos con los vecinos como los que significan: un no aceptar los planes que Dios va mostrando que tiene para la historia del pueblo. Por esta razón alude sólo rápidamente al tema de las alianzas como seguridad, cuando dice

$Y$ entonces, iqué cuenta te tiene encaminarte a Egipto para beber las aguas del Nilo?, o ¿qué cuenta te tiene encaminarte a Asur para beber las aguas del Río? (Jr. 2,18).

Para afirmar después que dichas alianzas son falsas y sólo pueden producir la decepción, porque Yahveh no está con, no puede ver a aquellos de quienes Israel se fia

¡Cuánta ligereza la tuya para cambiar de dirección! También de Egipto te avergonzarás como te avergonzastes de Asur. También de ésta saldrás con las manos en la cabeza. Porque Yahveh ha rechazado aquello en que confias, y no saldrás bien de ello (Jr. 2, 6-37).

Es también significativo el breve discurso, en estilo sapiencial de bendición y maldición, de Jr 17, 5-8:

Maldito sea aquel que fía en hombre, y hace de la carne su apoyo, y de Yahveh se aparta en su corazón... y no verá el bien cuando viniere... Bendito sea aquel que fía en Yahveh, pues no defraudará Yahveh su confianza. Es como árbol plantado a las orillas del agua, que a la orilla de la corriente echa sus raices. No temerá cuando... 
Aqui aparece con claridad cómo el confiar en el mortal y en su fuerza es lo mismo que apartar el corazón de Yahveh, es ir hacia la nada.

Es sin duda esta visión la que hace que Jeremías pueda ser presentado como uno de los grandes defensores de la búsqueda de los medios pacíficos como solución de los problemas políticos internacionales, de la no alineación en los bloques de fuerza existentes en todos los tiempos, etc. Esto es lo que queda patente en su postura en los últimos tiempos de Jerusalén, cuando procura que no se lleve a cabo la rebelión contra Babilonia, apoyada por Egipto, y llama a tratar pacíficamente con el poder de Nabucodonosor, haciendo ver cómo dicho poder no es de él, sino que le viene de Dios, quien se lo ha concedido temporalmente: no es, pues, un dios, sino que es de Dios.

El otro gran profeta de este tiempo, Ezequiel, también hace sus juicios sobre las alianzas con los extranjeros (sean asirios, babilonios o egipcios) y las considera verdaderas adulterios que momentáneamente producen placer, pero que a la larga son frustrantes y llegan a crear tal dependencia que no pueden ser olvidados aunque se quiera. Pero lo peor de la situación estriba en que dichos extranjeros han llegado a ocupar el lugar de Dios. Veámoslo en algunos versículos de su historia simbólica de Jerusalén y Samaria:

Samaria se prostituyó cuando me pertenecía a mí; se enamoró perdidamente de sus amantes, los asirios sus vecinos, vestidos de púrpura, gobernadores y prefectos, todos ellos jóvenes apuestos y hábiles caballeros. Les otorgó sus favores... No cejó en sus prostituciones comenzadas en Egipto.. Por eso yo la entregué en manos de sus amantes... Estos descubrieron su desnudez, se llevaron a sus hijos y sus hijas... (Ez. 23,5-10; cfr. 16,26-29; 23,11.14b-17. 19-20.22-23a.24-25a.27).

Aparece, pues, con toda claridad cómo toda la historia del pueblo, tanto Israel como Judá, ha sido un ejemplo de esta idolatría-adulterio que supone el aliarse y hacer confianza con los paises y las fuerzas extranjeros.

Las conclusiones de este primer punto desde la crítica profética son las siguientes: a) las grandes potencias siempre buscan su provecho e intereses, b) la salvación de Israel como pueblo no está en las alianzas con las grandes potencias, c) las armas por sí mismas no son eficaces para solucionar los conflictos de Israel como pueblo de Dios, d) la conversión al verdadero Dios tiene que ir unida al reconocimiento de que los puros medios político-militares, alianzas, armas, se convierten en definitiva en idolos y que por tanto no tienen fuerza para salvar, e) sólo volviendo a vivir apoyados en Yahveh, el Dios liberador, es decir, como pueblo unido, solidario, en comunión y participación, se puede recibir y vivir la salvación.

\section{Crítica profética del nacionalismo de Israel basado en su teología de la elección}

Como ya es sabido, la existencia de Israel tuvo su origen en la experiencia de que Dios estaba acompañando a los grupos dominados por Egipto cuando éstos fueron pasando a la nueva situación de pueblo unido, libre y autónomo, en una tierra nueva. Este paso de una situación a otra fue experimentado como 
la gran acción amorosa de Dios, como el gran pacto ofrecido por Dios al pueblo para el futuro. De aqui surgió la conciencia de elección que en adelante ya no abandonará a dicho pueblo y se convertirá en fuente de relación amorosa con Dios y en base de confianza para nuevas situaciones.

Esta conciencia, convertida en una ideología teológica de la elección, era lo suficientemente ambigua como para que fuese malentendida en la práctica, manipulada y falsificada. Y asi ocurrió con frecuencia.

En concreto, quiero recoger tres momentos muy significativos donde esta falsificación se dio y donde la crítica profética fue muy clara al respecto.

\section{a) La pujanza nacional bajo Jeroboam II o la idea de que Israel es inmejorable}

Corrían los años 760 en el reino de Israel. El clima era de cierto optimismo. El progreso económico era grande, la riqueza nacional iba en aumento, la administración de la justicia se profesionalizaba, la existencia de los bancos con sus créditos favorecía la inversión en nuevas técnicas y productos agrícolas, las obras públicas se multiplicaban, la vida comercial en Samaria y las grandes ciudades florecia, las fiestas religiosas en los santuarios promovidas por el poder eran muy concurridas. Todos estos factores y el hecho de que las grandes potencias, Asiria sobre todo, hubieran moderado, quizás por debilidad, sus ansias expansionistas e imperialistas, produjeron un clima y una sensación extendida de shalom, de seguridad, que por supuesto fue interpretado inmediatamente como consecuencia mecánica y automática de la elección.

Es en esta situación en la que el profeta Amós hizo ver qué significaba en realidad la elección. Amós $(1,3-2,16)$ recriminó, en contra de lo que la gente se esperaba, más duramente a Israel que a todas las naciones vecinas. Y lo hizo recordando los beneficios que Yahveh le habia hecho:

Yo habia destruido al amorreo delante de ellos... Y yo los hice subir a ustedes del pais de Egipto y los llevé por el desierto cuarenta años, para que poseyeran la tierra del amorreo. Yo suscité profetas entre sus hijos, y nazireos entre sus jóvenes, ¿no es asi, hijos de Israel?, oráculo de Yahveh (Am. 2,9-11).

$Y$ en 9,7-9 los israelitas son comparados a los kusitas, a los filisteos y a los arameos; ante Yahveh no tienen privilegios. El hecho de que Dios los haya amado intensamente no les daba ningún derecho especial, sin que, en todo caso, era fuente de responsabilidad. Como se dice con toda claridad Amós en 3,1-2.

El profeta intentó también sacar de la mente de Israel la idea que las guerras de Israel (Jeroboam II estaba haciendo grandes conquistas) eran las guerras de Yahveh. Amós, en cambio, habló de que la guerra de Yahveh estaba declarada contra Israel y de que los ejércitos israelitas, por tanto, sufrirían la gran derrota, sin que se pudieran sentir seguros ni siquiera en la gran ciudad de Samaria (Am. 5,3.18-20; 6,1-3.13). Con otras palabras encontramos la misma idea en el profeta contemporáneo de Amós, Miqueas. Este profeta vio como una osadía el que después de hacer lo que hacian fueran diciendo: “¿No es- 
tá Yahveh en medio de nosotros? „No vendrá sobre nosotros ningún mal!" (Mi. 3,11).

De todo lo anterior podemos concluir que la postura de Amós era la siguiente: elección es amor intenso de Dios, no es privilegio; llama a la responsabilidad de ser testigo de la relación Dios-pueblo; no es Yahveh; no se debe convertir en un ídolo, en fundamento de la seguridad nacional y en motivo de persecución para quien ponga en duda o critique la situación global de la nación.

\section{b) La complacencia como opio del pueblo o la idea de que Sion es inexpug- nable}

Nos encontramos en los últimos años del reino de Judá. Tras el reinado de Josías y, por lo tanto, tras su reforma, un cierto optimismo reinaba en Jerusalén; y esto a pesar de que el nuevo rey Joaquín I (hijo de Josias) era fruto de la imposición del faraón egipcio, quien habia vencido y matado a Josías en una balalla. Lo cierto es que el faraón no se metió demasiado, con tal de que el rey hiciera una política que beneficiara los intereses egipcios. La mayoría de las exigencias sociales de la reforma deuteronómica de Josías se fueron dejando de lado y de ésta sólo quedaban los aspectos más externos y que no comprometían a una vida justa: el culto exterior en el templo era lo más importante, servía para mantener la sensación de paz y de seguridad.

A esta seguridad nacida de la concepción del templo se anadía la idea de que el conjunto de Sión, precisamente porque el templo estaba en él y además porque estaba muy bien situado en una zona alta y rocosa y porque estaba rodeado de murallas, era inexpugnable. Esta inexpugnabilidad además habría quedado confirmada en diversas ocasiones históricas cuando Jerusalén había estado a punto de caer y en el último momento se había superado la crisis y no había caído, o al menos, no había sido destruida. Esto había ocurrido en el pasado y estaba ocurriendo también en el presente, especialmente en tiempos del sucesor de Joaquín I, Sedecías, cuando Nabucodonosor, quien atacó Jerusalén con ánimos de tomarla y destruirla ya de una vez, se debió retirar por muy variadas razones y no acabó de llevar a término sus intenciones; dichas razones, por supuesto, fueron interpretadas como muestra de que Dios no quería la caída de la ciudad, de su palacio, de sus murallas, de su templo.

En este contexto, el profeta Jeremías sufriria la más dura persecución, será linchado, juzgado, golpeado, reducido a prisión, privado de la libertad, condenado a muerte, acusado de colaboracionista y de pasarse al enemigo, tachado de no nacionalista; y todo porque se atrevió a insinuar la destrucción del templo, la caida de las murallas y la ciudad, la invasión del pais, la muerte del monarca y de sus ministros.

Así suenan sus palabras:

Como Silo (un santuario ya destruido) quedará esta casa, y esta ciudad será arrasada, sin quedar habitante (Jr. 26,9; cfr. 7,12-15).

Asimismo quebrantaré yo a este pueblo y a esta ciudad, como quien rompe un cacharro de alfarería, que ya no tiene arreglo (Jr. 19,11). 
Vendrá sin falta el rey de Babilonia y destruiré esta tierra y se llevará cautivos de ellas hombres y bestias (Jr. 36,29).

Ustedes, pues, no oigan a sus profetas, adivinos, soñadores, augures ni hechiceros, que les hablan diciendo: 'no servirán al rey de Babilonia,' porque cosa falsa les profetizan para alejarlos de su suelo, de suerte que yo los arroje y perezcan... (Jr. 27, 9-10).

Sometan sus cervices al yugo del rey de Babilonia, sírvanle a él y a su pueblo, y quedarán con vida... $(\mathrm{J} r .27,12)$.

No oigan, pues, las palabras de los profetas que les dicen: 'no servirán al rey de Babilonia,' porque cosa falsa les profetizan... (Jr. 27,14).

No les hagan caso. Sirvan al rey de Babilonia y quedarán con vida. ¿Para qué ha de quedar esta ciudad arrasada? (Jr. 27,17).

...asi dice Yahveh: 'yugo de hierro he puesto sobre la cerviz de todas estas naciones, para que sirvan a Nabucodonosor, rey de Babilonia, y le servirán...' (Jr. 28, 14).

Oye Jananias: no te envió Yahveh, y tú has hecho confiar a este pueblo en cosa falsa (Jr. 28,15).

Así dice Yahveh.. a toda la deportación...: edifiquen casas... procuren el bien de la ciudad a donde los he deportado y oren por ella a Yahveh.. No se embauquen los profetas... Pues asi dice Yahveh: ... yo los visitaré y confirmaré sobre ustedes mi favorable promesa de volverlos a este lugar... (Jr. 29,4-10).

Y asi la reacción que provocarán estas palabras:

¡Vas a morir! (Jr. 26,8).

Pasjur hizo dar una paliza al profeta Jeremias y le hizo meter en el calabozo (Jr. 20,2).

Y así que habia leído Yehudi tres o cuatro hojas, él (el rey) las rasgaba con el cortaplumas del escriba y las echaba al fuego del brasero... Ni se asustaron, ni se rasgaron los vestidos el rey ni ninguno de sus siervos que oían todas estas cosas (Jr. 36, 23-24).

Luego el rey ordenó... apoderarse del escriba Baruk y del profeta Jeremías.. (Jr. 36,26).

Entonces tomó el profeta Jananias el yugo de sobre la cerviz del profeta Jeremías y lo rompió; y habló Jananias delante de todo el pueblo: 'así dice Yahveh: así romperé el yugo de Nabucodonosor... (Jr. 28,10-11).

Semaías... despachó cartas... diciendo: .... ipor qué no has sancionado a Jeremias de Anatot que se te hace pasar por profeta? (Jr. 29,24-27).

Esta es, pues, la postura de Jeremias: pone en duda la seguridad de la ciudad, anuncia la invasión, recomienda hacer las paces con los enemigos, exhorta al ejército a no luchar, busca que el pueblo viva fraternalmente en torno a Yahveh.

Las reacciones ante esta postura nos muestran con claridad la postura "nacionalista" que no puede soportar ninguna crítica contra su manera de ver 
y hacer las cosas, que no quiere, por tanto, ningún tipo de cambio auténtico o conversión, que, por propio interés, no se preocupa realmente del futuro del pueblo.

¡Busquen a Yahveh y vivirán,...! (Am. 5,6a).

Busquen el bien, no el mal, para que vivan, y que asi sea con ustedes Yahveh Sebaot, tal como dicen. Aborrezcan el mal, amen el bien, implanten el juicio en la Puerta; quizás Yahveh Sebaot tenga piedad del resto de José (Am. 5,14-15).

Yo te desposaré conmigo para siempre; te desposaré conmigo en justicia y en derecho, en amor y en compasión; te desposaré conmigo en fidelidad, y tú conocerás a Yahveh (Os. 2,21-22).

Porque yo quiero amor, no sacrificio, conocimiento de Dios, más que holocaustos (Os. 6,6).

Aprendan a hacer el bien, busquen lo justo, den sus derechos al oprimido, hagan justicia al huérfano, aboguen por la viuda (Is. 1,17).

Porque el yugo que les pesaba y la barra de su hombro - la vara de su tirano - has roto, como el día de Madián. Porque toda bota que taconea con ruido (la bota militar) será para la quema, pasto del fuego (Is. 9,3-4).

(El mesías) no juzgará por las apariencias, ni sentenciará de oidas. Juzgará con justicia a los débiles, y sentenciará con rectitud a los pobres de la tierra... Serán vecinos el lobo y el cordero... La vaca y la osa pacerán... Hurgará el niño de pecho en el agujero del áspid... Nadie hará daño, nadie hará mal en todo mi santo monte, porque la tierra estará llena de conocimiento de Yahveh, como cubren las aguas el mar (Is. 11,3-9).

Sucederá en dias futuros que el monte de la Casa de Yahveh será asentado en la cima de los montes y se alzará por encima de las colinas. Confluirán a él todas las naciones, y acudirán pueblos numerosos. Dirán: 'vengan subamos al monte de Yahveh, a la Casa del Dios de Jacob, para que él nos enseñe sus caminos y nosotros sigamos sus senderos.'

Pues de Sión saldrá la Ley, y de Jerusalén la Palabra de Yahveh. Juzgará entre las gentes, será árbitro de pueblos numerosos. Forjarán de sus espadas azadones, y de sus lanzas podaderas. No levantará espada nación contra nación, ni se ejercitarán más en la guerra (Is. 2,2-4).

Y sucederá aquel día que yo extirparé de en medio de ti a tus caballos, y haré desaparecer tus caballeros; extirparé las ciudades de tu tierra, y demoleré todas tus fortalezas; extirparé de tu mano las hechicerias, y no habrá para ti más adivinos; extirparé tus estatuas... y ya no podrás postrarte más ante la obra de tus manos... (Mi. 5,9-12).

Se te ha declarado, hombre, lo que es bueno, lo que Yahveh de ti reclama: tan sólo practicar la justicia, amar la solidaridad y caminar humildemente con tu Dios (Mi. 6,8). 


\section{c) El desprecio de las naciones o la negación de su papel en el proyecto salvifico de Yahveh}

Para acabar este segundo apartado sobre la crítica profética a la teología de la elección y a la religión nacionalista de Israel, me parece muy importante un tema profético que juega un papel fuertemente relativizador de dichas teología y religión. Me limitaré a insinuarlo y a ofrecer algunas citas de los libros proféticos donde aparece con claridad.

Quien más quien menos los profetas, en momentos diferentes de la historia del pueblo, hablan sobre las naciones. Tanto es así que en los libros de los profetas normalmente encontramos un relativamente extenso apartado en el que se recogen los llamados "oráculos contra las naciones."

Es seguro que Israel escuchaba con complacencia dichas palabras porque las veía como una fundamentación de la exclusividad de la elección, interpretada como rechazo divino de las naciones y como privilegio propio. Los profetas, en cambio, no comparan esta interpretación, sino que la relativizan con fuerza.

Son reveladores, en este sentido, las muchas ocasiones en que los profetas hablan de los diferentes imperios invasores de Israel o de Judá, como de imperios que juegan el papel de ser instrumentos de los planes salvíficos de Yahveh. Dichos imperios son presentados a menudo, según las circunstancias, como ejecutores del juicio de Yahveh, como bastón de su ira, como martillo, o también como instrumentos de la salvación que Yahveh tiene decidida para su pueblo, como sus nuevos libertadores (cfr. Is. 7,18; B, 7; 10,5-27; Am. 3,11; etc. sobre Asiria; Hab. 1,5-11; Jr. 5, 14-19; 51,20-23; etc. sobre Babilonia; Is. 41,1-29; 44,24-28; 45,1-7; 48,12-15; etc. sobre Ciro).

Muy en consonancia con estas palabras y en la misma línea están aquéllas por medio de las cuales los profetas atacan a dichos imperios por haberse engreído y no haber caído en la cuenta de que su papel es limitado. Su orgullo y arrogancia son la razón de su derrota futura por voluntad de Yahveh. Un ejemplo claro de esto lo tenemos en Jr. 50,21-32.

Lo más llamativo del caso es que en algunas ocasiones los profetas se atreven a llamar al emperador de turno de dichos imperios "siervo de Yahveh." Tal es el caso de Nabucodonosor el babilonio en Jr. 25,9; 27,6;43,10; y el de Ciro en las muchas ocasiones en que el Segundo Isaías habla de él, de las cuales he citado hace poco algunas.

Queda claro, pues, por medio de todas las afirmaciones proféticas anteriores, que la teología de la elección y la religión nacionalista tal como las entendía Israel no se sustentan. Yahveh es quien como señor conduce en el fondo la historia y quien para ellos se sirve de quien quiere, de su pueblo y del resto de las naciones; todos los países entran en realidad en la dinámica de la voluntad salvífica de Dios y en sus proyectos historicos. 


\section{Crítica de la privatización de la nación en manos de unos pocos y de la desigualdad entre hermanos}

No voy a alargarme mucho en este y en los dos siguientes puntos, pues ya los he tratado en otro lugar. Es importante recordarlos, aunque sea someramente, pues ofrecen el contrapunto a lo que debe ser el verdadero ideal del pueblo de Israel: no el propio poder ni las alianzas con los poderosos, sino la constitución de un pueblo en justicia y fraternidad. De ahí la conocida crítica profética a la injusticia y a la alienación religiosa y la propuesta de la verdadera sociedad utópica.

Como ya es sabido, la experiencia del éxodo, que supone el descubrimiento de que Yahveh es el Dios liberador de todo dominio, provoca inmediatamente la unión de grupos muy diferentes y la formación de un pueblo que se compromete a vivir fraternalmente. Exodo y pueblo fraternal, por tanto, son dos realidades inseparables. Y sin embargo, la separación que parecía imposible se da con frecuencia en el pueblo de Israel. Surgen inmediatamente personas y grupos que toman la nueva nación como propiedad privada y que provocan así el empobrecimiento y esclavitud real de la mayorla, especialmente entre el mundo de los campesinos.

Quienes desgraciadamente toman la delantera en esta carrera hacia una sociedad injusta, competitiva en el peor sentido de la palabra, desigual en las oportunidades, etc.; quienes toman la delantera, repito, son los reyes, aquellos que debian ser pastores y servidores del pueblo.

Ya Salomón, con la creación de un imperio al estilo oriental (gran ejército, gran número de cortesanos, gran harem, grandes construcciones, gran templo, etc.), con la divinización del propio poder, con la imposición de grandes impuestos para llenar las arcas del Estado, empezo a hacer realidad la separación entre rey y súbditos, entre hermanos (unos pasaron a ser servidores de otros), haciendo asi surgir las criticas de algunos creyentes, tal como aparece en $1 \mathrm{Sm}$. 8,11-18 (cfr. también Jc. 9, la famosa fábula de Jotam contra la monarquí, y otros muchos textos como Di. 17,14-20; Os. 7,3-7; 13,9-11; Ez. $34,1-10$, etc., en los cuales en diferentes momentos de la historia de Israel se volvió sobre las mismas críticas a la realidad monárquica.

El poderoso rey de Israel, Ajab, siguió en la misma línea cuando, según se nos narra en I Re. 21, fundado en la concepción baalista de la monarquía despótica se creyó con el derecho de quitar de en medio a un pequeño propietario para quedarse con sus tierras y enriquecer asi su propio patrimonio. Tampoco en este caso faltó la crítica profética a tal actuación, en la persona de Elias.

También el reinado de Jeroboam Il supuso un desgraciado avance en esta concepción despólica del poder, tal como aparece er toda la actuación profética de Amós, ya mencionada, y en su consiguiente persecución.

Para acabar esta breve enumeración de reyes que se distinguieron tristemente por su colaboración en destruir la imagen de la sociedad fraternal surgida del éxodo, basta recoger las palabras de Jeremías dirigidas al rey de tumo, Joaquín I, palabras que, por cierto, agudizan la persecución contra el profeta de parte de la autoridad: 
¡Ay del que edifica su casa sin justicia y sus pisos sin derecho! De su projimo se sirve de balde y su trabajo no le paga (Jr. 22,13).

Pero conviene no centrar sólo en los reyes esta destrucción de lo que hubiera podido ser. Muchas otras instituciones y personas principales, oficiales de la corte, burócratas, banqueros, comerciantes, sacerdotes, profetas, etc., movidos por su deseo de engordar a costa del enflaquecimiento de la mayoria, contribuyeron en gran manera a la separación de clases en Israel y a la explotación de unos por los otros.

Basta citar algunos de los textos proféticos en donde dichas instituciones y personas fueron denunciados: Am. 5,11: contra los impuestos injustos para enriquecimiento personal. Am. 2,7; Is. 1,23; 3,14s; Mi. 2, 1-2.8-11; So. 1,9; Jr. 2,34; Ez. 22,29: contra la ambición y la avaricia de quienes para tener más llegan a destruir y aniquilar las vidas de los pobres. Am. 3,9.15; 4,1; 6,3-5; Is. 3,18-24; Jr. 23,14-15: contra el lujo, las grandes fiestas, las grandes construcciones de quienes se despreocupan totalmente del futuro del pueblo sencillo. Am. 2,6; 5,7.12; 6,12; Mi. 3,1-3.9-11; 7,1-3: contra quienes, aprovechándose de su poder judicial, dan la razón a quienes les pagan y echan a perder asl a los pobres, quitándoles lo que es suyo, arrancándoles la piel, comiéndoselos como si de alimento se tratara y haciéndolos desaparecer así de sobre el pals. Am. 8,4-6; Mi. 6,9-12: contra los comerciantes que están esperando que pasen los dias festivos para volver al negocio y hacerse ricos, falseando las balanzas, las medidas, imponiendo los precios que quieren a los pobres necesitados, especulando con la moneda. Jr. 22,13; Dr. 24, 14-15; Lv. 19,13: contra quienes explotan a los jornaleros, haciéndoles trabajar sin pagarles a su tiempo o pagándoles menos de lo que les es debido.

Todas estas denuncias recogidas aquí a modo de ejemplo son una muestra palpable de cómo se ha roto la fraternidad y cómo no existe ya solidaridad ni preocupación por el bien común (cfr. Am. 6,4-6); son una muestra, dicho en otras palabras, de que unos pocos viven apoderándose de las riquezas y del pais, mientras que la mayoria apenas tienen ya para subsistir y dejan asi de existir, de ser seres humanos.

\section{Crílica del nacionalyahvismo y de la religión alienante}

Todas las actitudes y acciones del apartado anterior no deben ser consideradas como simplemente de circunstancias, coyunturales. Tienen una base, un fundamento mucho más profundos.

Lo que está en el fondo es una falsa concepción de lo religioso, una inautenticidad en la relación con Dios, centrada ésta en el culto, en la liturgia, en el templo, en las prácticas legales; una relación con Dios que no tiene nada que ver con la vida en su aspecto personal y social.

Y si en algunos casos parece que la vida está dirigida por tal relación con Dios, éste es un dios ralso, un dios que nada tiene que ver con Yahveh el Dios liberador, el Dios que llama a construir una comunidad fraternal, el Dios que defiende a los que no tienen defensor (forasteros, levitas, huérfanos, viudas y pobres). Se trata, pues, de un dios de conveniencias politicas, sociales, el dios 
nacional, un dios que no es garante de la justicia, sino que justifica la injusticia y la violencia institucionalizada. Es el dios del nacionalyahvismo, el dios alienante, el dios tapadera de todas las situaciones inhumanas y que adormece para que no sean éstas desenmascaradas y eliminadas.

Esto explica la dura crítica que los profetas hacen al culto. Vale la pena ahora dejar hablar a los mismos profetas, recogiendo algunos de sus textos en los que aparece esta crítica, aparentemente blasfema, a las prácticas religiosas.

Yo detesto, desprecio sus fiestas, no me gusta el olor de sus reuniones solemnes. Si me of recen holocaustos... no me complazco en sus oblaciones, ni miro a sus sacrificios... iAparta de mi lado la multitud de tus canciones, no quiero oír la salmodia de tus arpas! (Am. 5,21-23).

¿Acaso sacrificios y oblaciones en el desierto me ofrecieron, durante cuarenta años, casa de Israel? (Am. 5,25).

¿A mi qué, tanto sacrificio suyo?... Harto estoy de holocaustos... y sangre de novillos y machos cabríos no me agrada, cuando vienen a presentarse ante mi. ¿Quién ha solicitado de ustedes esa pateadura de mis atrios? No sigan trayendo oblación vana: el humo del incienso me resulta detestable... no tolero falsedad y solemnidad. Sus novilunios y solemnidades aborrece mi alma: ...y al extender ustedes sus palmas, me tapo los ojos para no verlos. Aunque menudeen la plegaria, yo no oigo (Is. 1,11-15).

Dice el Sefhor: por cuanto ese pueblo se me ha allegado con su boca, y me han honrado con sus labios... (Is. 29,13).

¿Con qué me presentaré yo a Yahveh, me inclinaré ante el Dios de lo alto? ¿Me presentaré con holocaustos, con...? ¿Aceptará Yahveh miles de cameros...? ¿Daré mi primogénito por mi delito...? (Mi. 6,6-7).

¿A qué traerme incienso de Seba...? Ni sus holocaustos me son gratos, ni sus sacrificios me complacen (Jr. 6,20).

No se fien en palabras engañosas diciendo: 'templo de Yahveh, templo de Yahveh, templo de Yahveh es éste' $(\mathrm{Jr} .7,4)$.

¿Acaso es éste el ayuno que yo quiero el día en que se humilla el hombre? ¿Habia que doblegar como junco la cabeza, en sayal y ceniza estarse echado? ¿A eso llaman ayuno y día grato a Yahveh? (Is. 58,5).

La realidad es que este culto sólo vale para perdición porque

sus manos están llenas de sangre (Is. 1,15b).

Mientras que su corazón está lejos de mi, y el temor que me tiene son preceptos ensefiados por hombres (Is. 29,13).

Pero he aqui que ustedes se fian en palabras engañosas que de nada sirven para robar, matar, adulterar, jurar en falso, incensar a Baal y seguir a otros dioses que no conocian. Luego vienen y se paran ante mi en esta casa llamada por mi Nombre y dicen: 'iestamos seguros!' para seguir haciendo todas esas abominaciones (Jr. 7,8-10).

Es que el día en que ayunaban, buscaban su negocio y explotaban a todos sus trabajadores. Es que ayunan para litigio y pleito... (Is. 58, 3b-4a). 
Cuando han ayunado y plañido en el quinto y séptimo mes, y esto durante setenta años, ihan ayunado de verdad por mi? $(\mathrm{Za} .7,5)$.

No vale, pues, este tipo de relación con Dios. El la aborrece, porque no se le dirige a El, sino a un dios falso, (cfr. también Sir. 34,18-35,24). ¿Cuál es, pues, la relación que Dios quiere?

\section{Anuncio profético de la utopía}

Lo único que Dios quiere es que se lo encuentre de nuevo alli donde El está, es decir, en la vida de fraternidad, de justicia, de solidaridad, de comunión. Esto, ¿por qué?

Porque El sigue siendo el que llama a la utopia humana, una utopia que comienza cuando se da el paso de la esclavitud a la libertad plena y compartida por todos, pero que no se hace realidad hasta que se implante realmente la justicia en la tierra y con ella la verdadera paz social. Una paz que nace de la destrucción de las armas, pero que nace sobre todo de la solidaridad fraternal, de la comunión, del cambio del corazón humano en un corazón que tenga el mismo latir de Dios de la misericordia.

Muchos profetas nos hablan de esta llamada a la utópía y de este Dios de la misericordia. Con esta llamada no hacen más que poner unas pistas, unas vías, para que el hombre, nosolros, realmente sepamos por donde ir, si es que queremos ser realmente humanos, si queremos realizar una comunidad a la medida de los sueños y de los proyectos de Dios.

Quiero acabar recogiendo algunos textos proféticos que hacen pensar y que ciertamente explican mejor que mis palabras esta utopia humano-divina.

Yo recogeré el Resto de mis ovejas, de todas las tierras a donde las empujé, las haré tornar a sus estancias, criarán y se multiplicarán. Y pondré al frente de ellas pastores que las apacienten, y nunca más estarán miedosas ni asustadas, ni faltará ninguna. Miren que dias vienen en que suscitaré a David un germen justo: reinará un rey prudente y la justicia en la tierra. En sus dias estará a salvo Judá e Israel vivirá en seguro. $Y$ éste es el nombre con que le llamarán: "Yahveh, justicia nuestra" (Jr. 23,2-6).

He aquí que dias vienen en que pactaré con la casa de Israel... una nueva alianza...: pondré mi ley en su interior y sobre sus corazones la escribiré, y yo seré su Dios y ellos serán mi pueblo... todos ellos me conocerán del más chico al más grande -oráculo de Yahveh-... (Jr. 31,31-34).

...yo mismo cuidaré de mi rebaño y velaré por él. ...Yo mismo apacentaré a mis ovejas y yo las llevaré a reposar... Buscaré la oveja perdida, tornaré a la descarriada, curaré a la herida, confortaré a la enferma; pero a la que está gorda y robusta la exterminaré: las pastorearé con justicia... y yo vendré a salvar a mis ovejas para que no estén más expuestas al pillaje; voy a juzgar entre oveja y oveja... Concluiré con ellos una alianza de paz, haré desaparecer de esta tierra las bestias feroces... El árbol del campo dará su fruto, la tierra dará sus productos, y ellos vivirán en seguridad en su suelo. Y sabrán que yo soy Yahveh, cuando despedace las barras de su yugo y los libre de la mano que los tiene esclavizados... (Ez. 34, 11-31). 
$Y$ les daré un corazón nuevo, infundiré en ustedes un espíritu nuevo, quitaré de su carne el corazón de piedra y les daré un corazón de carne... Ustedes seréis mi pueblo y yo seré su Dios (Ez. 36,26-28).

El espíritu del Señor Yahveh está sobre mí, por cuanto que me ha ungido Yahveh. A anunciar la buena nueva a los pobres me ha enviado, a vendar los corazones rotos; a pregonar a los cautivos la liberación y a los reclusos la libertad... (Is. 61,1-2).

¿No será más bien este otro el ayuno que yo quiero: desatar los lazes de la maldad, deshacer las coyundas del yugo, dar la libertad a los quebrantados, y arrancar todo yugo? ¿No será partir al hambriento tu pan, y a los pobres sin hogar recibir en casa? ¿Que cuando veas a un desnudo lo cubras $y$ de tu semejante no te apartes? (1s. 58,6-7).

\section{Conclusion}

Este breve recorrido por los profetas muestra su respuesta a los problemas fundamentales de Israel como pueblo histórico y como pueblo de Dios. Estos problemas siguen extendiendo en el mundo de hoy y exigen también una respuesta. Es verdad que no se puede aplicar anacrónica e inmediatistamente lo que ellos dijeron al mundo actual. Incluso en el lapso de cuatro siglos que hemos analizado no todas sus respuestas se pueden sintetizar con absoluta coherencia pues responden a coyunturas concretas. Pero dos importantes leccione al menos se deducen de lo dicho.

La primera es que ninguna sociedad tiene un futuro digno del hombre, co-i mo no lo tuvo Israel, si no se basa en la justicia interna y en concreto si no se vuelve hacia los más pobres. Cualquier otro modo de pretender construir el futuro (alianzas, armamentisıno, sometimientos a los bloques de poder etc.) es radicalmente insuficiente sin la justicia, además de ser con frecuencia pecaminoso. Eso es lo que afirman los profetas invocando la fe en Yahveh, tanto con la denuncia profética como con el anuncio utópico. Invocar la fe en Yahveh, como lo hacen los profetas, tiene un sentido directamente religioso, pero acompañado siempre de una finalidad histórica: construir el nuevo cielo y la nueva tierra.

La segunda es que, sin esa práctica de la justicia, ninguna ventaja tienc la elección. Las teocracias como sistemas políticos son ya anacrónicas en el mundo occidental, pero no la utilización de la elección para conseguir una falsa seguridad y para oprimir a otros. El mundo occidental no tiene ninguna ventaja ante Dios para subsistir porque se llame cristiano; y no tiene, por supuesto, ningún derecho a usar de esa supuesta elección para justificar horrores y abominaciones.

Esa doble lección es lo que sigue haciendo actual a los profetas. Desenmascarar el pecado que siempre quiere ocultarse y cubrirse incluso con cl nombre de Dios y apuntar a la verdadera voluntad de Dios para este mundo. 